\title{
Long term outcome and quality of life after pelvic exenteration for recurrent endometrial and cervical cancers
}

\author{
Charlotte Ngô $^{1,2 \#}$, Christelle Abboud ${ }^{1}$, Paul Meria ${ }^{1}$, Virginie Fourchotte ${ }^{1}$, Pascale Mariani ${ }^{1}$, \\ Bernard Baranger ${ }^{1}$, Xavier Sastre ${ }^{3}$, Caroline Malhaire ${ }^{4}$, Anne-Cécile Philippe ${ }^{1}$, Suzy Scholl ${ }^{5}$, \\ Anne de la Rochefordière ${ }^{6}$, Séverine Alran ${ }^{1}$

\begin{abstract}
${ }^{1}$ Departments of Surgical Oncology, Institut Curie Gynaecological Cancer Study Group, Institut Curie, Paris, France
${ }^{2}$ Université Paris Descartes, Institut Curie Gynaecological Cancer Study Group, Institut Curie, Paris, France

${ }^{3}$ Departments of Pathology, Institut Curie Gynaecological Cancer Study Group, Institut Curie, Paris, France

${ }^{4}$ Departments of Radiotherapy, Institut Curie Gynaecological Cancer Study Group, Institut Curie, Paris, France

${ }^{5}$ Departments of Medical Oncology, Institut Curie Gynaecological Cancer Study Group, Institut Curie, Paris, France

${ }^{6}$ Departments of Medical Imaging, Institut Curie Gynaecological Cancer Study Group, Institut Curie, Paris, France
\end{abstract} \\ Email: " charlotte.ngo@curie.net
}

Received 25 April 2013; revised 27 May 2013; accepted 5 June 2013

Copyright (C) 2013 Charlotte Ngô et al. This is an open access article distributed under the Creative Commons Attribution License, which permits unrestricted use, distribution, and reproduction in any medium, provided the original work is properly cited.

\begin{abstract}
Introduction: Pelvic exenteration can cure recurrent gynecological malignancies. However, treatment morbidity is over $50 \%$ in radiated pelves. We evaluated the outcome, the morbidity and the quality of life after exenteration. Methods: Patients who underwent an exenteration for recurrent cervical or endometrial cancer in our institution between 1999 and 2011 were retrieved. Survival rates were calculated according to Kaplan-Meier method and compared using the logrank test. The EORTC QLQ-C30 and QLQ-CX24 questionnaires were sent to patients alive in January 2012. Results: We identified 25 patients: 17 (68\%) had cervical cancer and 8 (32\%) endometrial cancer. $92 \%$ of them had received radiotherapy previously. All patients had a central pelvic recurrence, within a median time of 30 months [4 - 384] from initial treatment. Early complications requiring a re-laparotomy occurred in 9 patients (36\%). Late complications included $2(8 \%)$ fistulas, $2(8 \%)$ occlusion and $1(4 \%)$ ureteral stenosis. Complete resection was obtained in 92\% of patients. Disease Free and Overall survival rates were better in cervical rather than in endometrial cancer (median DFS in months 17 [2 - 145] vs 9.5 [3 - 21], $p=0.064$, median OS in months 20 [2 - 145]

\footnotetext{
*All the authors declare that they have no conflicts of interest.

This study has been presented in part in the 14th Biennal Meeting of the International Gynecologic Cancer Society, Vancouver October 13$16,2012$.

${ }^{\#}$ Corresponding author.
}

vs 13 [4 - 42], $p=0.019) .69 \%$ of patients answered the quality of life questionnaires. Mean global quality of life score was 45 on a scale of 0 - 100, none of the patients had a sexual activity. Conclusions: Morbidity of exenteration remains high and quality of life is altered. Endometrial cancer is associated with a poorer prognosis. In those patients, exenteration should be put in balance with best supportive care.

Keywords: Pelvic Exenteration; Quality of Life; Recurrent Cervical Cancer; Recurrent Endometrial Cancer

\section{INTRODUCTION}

Pelvic exenteration is the only therapeutic option providing a chance to cure recurrent central pelvic malignancies in patients previously irradiated [1].

Cervical carcinoma displays recurrence rates related to clinical stage as follows: stage FIGO IB 10\%, stage FIGO IIA $17 \%$, stage FIGO IIB $23 \%$, stage FIGO III $42 \%$ and stage FIGO IV 74\% [2]. Most of recurrences occur within 3 years after primary treatment $(80 \%$ to $95 \%)$ and prognosis is poor with a 5-year survival rate ranging from $6 \%$ to $77 \%[3,4]$. Early stage endometrial carcinoma has good prognosis, though recurrence occurs in $15 \%$ of stage I disease $[5,6]$. Most frequent recurrence site is the vaginal cuff and $80 \%$ of relapses occur within 3 years after primary treatment [5-7]. This risk of recurrence is decreased by adjuvant pelvic radiotherapy in 
high risk patients (Stage IB grade 3, lymphovascular invasion, stage II and higher) [8,9]. Patients with locoregional recurrence of endometrial carcinoma have poor outcome with a low 5-year survival rate, ranging from $18 \%$ to $44 \%[5,6,10]$.

The most common indication for exenteration is persistent or recurrent cervical carcinoma (about 70\%) [1], while there are no precise guidelines on management of recurrent endometrial carcinoma when primary treatment has included both surgery and radiotherapy. Pelvic exenteration has been widely used since its first description in 1948 by Brunschwig [11]. Nowadays, perioperative mortality is low, from $0 \%$ to $5 \%$. Five-year survival rates range from $20 \%$ to $55 \%$ but morbidity still exceeds $50 \%$ and quality of life is impaired [1]. It is still unclear whether exenteration provides a good balance between expectancy of a cure and reasonable quality of life since prospective randomized studies are difficult to conduct in those relatively rare situations.

The aims of our study were to analyze long term outcomes and quality of life in patients undergoing pelvic exenteration, to compare outcome in recurrent cervical cancer and recurrent endometrial cancer, and if possible to define patient selection criteria for such an extensive procedure.

\section{PATIENTS AND METHODS}

Using a computerized database, we identified and reviewed retrospectively patients who underwent a pelvic exenteration at the Institut Curie between January 1999 and November 2011, for recurrent endometrial or cervical cancer. Inclusion criteria in the study were: patients with proven recurrent cervical or endometrial cancer who underwent pelvic exenteration. The surgical procedure was performed by a team including gynaecologist, urologist and digestive surgeons. For each patient, the exenterative procedure was approved by an interdisciplinary comitee.

All patients had a clinical and gynaecological examination and an extension assessment including thoracoabdomino-pelvic imaging (MRI and/or CT scan and/or FDG-PET/CT). The procedure was intended as a curative measure in the absence of distant metastasis and if the comorbidities profile of the patient allowed such a radical surgery. In case of distant metastasis, surgery was intended as a palliative measure if fistulae or occlusion. The procedure was performed through laparotomy. According to the local extension, we performed posterior exenteration alone, anterior exenteration, including colpectomy and cystectomy, or total exenteration with the additional resection of the rectum and in some cases part of the perineum. Additional procedures could be performed according to pre-operative assessment of local extension and according to intra-operative observations. All patients received an intra-operative antimicrobial prophylaxis and a postoperative anticoagulation with low weight molecular heparin. Patients received adjuvant treatment according to the pathological results and to the previous treatments received. All patients underwent regular follow-up with clinical and gynaecological examination every 3 - 4 months for the initial 3 years and every 6 months for the following years. Abdomino-pelvic imaging (MRI or CT scan) was performed at first visit and then according to the physician indication.

For each patient, the following characteristics were recorded: age at diagnosis of the first cancer, age at exenteration, initial FIGO stage, site of recurrence, previous treatments, timing between primary diagnosis and relapse, surgical procedure, biological markers, characteristics of operative management (operation duration, type of resection, type of urinary diversion, transfusion, length of stay in intensive care unit), postoperative morbidity (early complications occurring within 2 months, late complications occurring after 2 months), adjuvant treatment.

Quality of life was assessed in the patients who were still alive on January 2012. Patients received the European Organization of Research and Treatment of Cancer (EORTC) Core Questionnaire, the EORTC QLQ-C30 in the French validated version 3.0. This questionnaire consists of five functional scales measuring physical, emotional, role, cognitive and social functioning. It also includes three symptoms scales measuring pain, fatigue, and nausea and vomiting, six single items (dyspnea, diarrhea, constipation, insomnia, loss of appetite and financial difficulties), and a general quality of life scale. Women were also asked to fill out the EORTC QLQCX24, a questionnaire developed to determine the quality of life of patient with cervical cancer that addresses especially abdominal complaints and menopausal symptoms, lower limbs symptoms, vaginal symptoms, body image and sexuality. All questionnaires were sent in January 2012. Patients answer the questionnaires at home. The scales and items of the questionnaires were transformed to a scale of 0 - 100 using a scoring manual. A high score on a functioning scale of quality of life implied good functioning or quality of life, while a high score on a symptom scale or single item indicated a high degree of disturbance.

All statistical results were presented in raw numbers, rates, means (95\% standard error), medians [ranges]. Progression free survival (PFS) and overall survival (OS) were calculated according to the Kaplan-Meier method. Durations of survival were calculated from the day of pelvic exenteration. Endpoint was any death for OS and tumour progression for PFS. The patients lost were censored at the date of the last follow-up observation. Survival curves were compared using the log-rank test. All 
reported significance was two-tailed at a level of 0.05 . All statistical analyses were performed using the Statview software for Microsoft Windows.

\section{RESULTS}

\subsection{Characteristics of Patients}

We identified 25 patients who underwent pelvic exenteration for recurrent malignancies from 1999 to 2011. Median time between the primary diagnosis and first relapse was 30 months (range 4 - 384). Median age at surgery was not significantly different between patients with cervical and endometrial carcinoma (60.5 [55 - 74] vs 52.5 [46 - 81], $\mathrm{p}=0.29)$. Previous treatments included external radiation and/or brachytherapy in 23 patients $(92 \%)$. The pre-operative assessment at recurrence included a clinical and gynaecological examination for all patients, 14 patients $(56 \%)$ underwent a pelvic examination under general anesthesia with cystoscopy, 17 patients $(68 \%)$ underwent a CT scan, 12 patients (48\%) had a MRI and 10 patients $(40 \%)$ had a FDG-PET/CT. $88 \%$ of the patients underwent a biopsy prior to exenteration which proved the recurrence. Three patients $(12 \%)$ were operated on without prior biopsy but with evident recurrence on repeated imaging including FDG-PET/CT scan. All patients developped a central relapse. 1 patient had a distant hepatic metastasis associated and was operated in a palliative intent to avoid an occlusion. Characteristics of patients are summarized in Table $\mathbf{1}$.

\subsection{Operative Management and Peri-Operative Morbidity}

Types of resection are summarized in Table 2. Additional procedures included one vulvectomy for associated intravulvar neoplasia. This patient had a pedicled tension free greater omentum flap placed in the pelvis. There was no vaginal reconstruction. Major postoperative complications requiring re-laparotomy occurred in 9 patients (36\%) including: peritonitis, pelvic abcess, leakage of intestinal anastomosis, leakage of ureteral anastomosis and rectovaginal fistula. There was no perioperative death. On the 24 patients operated in a curative intent, complete resection (R0) was obtained in 22 patients $(92 \%) .2$ patients had involved margins, for one of them, the tumour extension to the lateropelvic wall was discovered during surgery. Late complications occurred in 6 patients $(24 \%)$. Among those, 2 patients required a reoperation. Operative management and perioperative morbidity are summarized in Table 2 .

\subsection{Follow-Up and Survival}

Median follow-up from surgery was 40 months range
Table 1. Characteristics of patients with recurrent gynaecological tumors, $\mathrm{N}=25$.

\begin{tabular}{|c|c|}
\hline Characteristics & $\begin{array}{l}\text { N (\%) or median } \\
\text { [range] }\end{array}$ \\
\hline $\begin{array}{l}\text { Age at primary diagnostic } \\
\text { Age at exenteration }\end{array}$ & $\begin{array}{l}50.5[36-79] \\
56.5[46-81]\end{array}$ \\
\hline $\begin{array}{l}\text { Primary tumor } \\
\text { Endometrial cancer } \\
\text { Cervical cancer }\end{array}$ & $\begin{array}{c}8(32 \%) \\
17(68 \%)\end{array}$ \\
\hline $\begin{array}{l}\text { Cervix } \\
\text { Adenocarcinoma } \\
\text { Squamous cell carcinoma }\end{array}$ & $\begin{array}{l}3(18 \%) \\
14(82 \%)\end{array}$ \\
\hline $\begin{array}{l}\text { Endometrium } \\
\text { Endometrioid } \\
\text { Sero-papillar } \\
\text { Other }\end{array}$ & $\begin{array}{c}6(75 \%) \\
1(12.5 \%) \\
1(12.5 \%)\end{array}$ \\
\hline $\begin{array}{l}\text { Initial FIGO stage } \\
\text { I } \\
\text { IIA } \\
\text { IIB } \\
\text { III } \\
\text { IV } \\
\text { Missing data } \\
\text { N+ }\end{array}$ & $\begin{array}{c}12(48 \%) \\
2(8 \%) \\
3(12 \%) \\
3(12 \%) \\
1(4 \%) \\
4(16 \%) \\
5(20 \%)\end{array}$ \\
\hline $\begin{array}{l}\text { Prior treatment } \\
\text { Radiotherapy }+/ \text { - brachytherapy } \\
\text { Pelvic median dose } \\
\text { Surgery } \\
\text { Chemoradiation }\end{array}$ & $\begin{array}{c}23(92 \%) \\
50 \mathrm{~Gy}[45-100] \\
22(88 \%) \\
5(20 \%)\end{array}$ \\
\hline $\begin{array}{l}\text { Prior surgical procedure } \\
\text { Hysterectomy } \\
\text { Wertheim } \\
\text { Lymphadenectomy }\end{array}$ & $\begin{array}{c}13(52 \%) \\
9(37 \%) \\
14(56 \%)\end{array}$ \\
\hline $\begin{array}{l}\text { Prior complete resection or complet } \\
\text { Yes } \\
\text { Missing data }\end{array}$ & $\begin{array}{c}23(92 \%) \\
2(8 \%)\end{array}$ \\
\hline $\begin{array}{l}\text { Site of recurrence } \\
\text { Central relapse } \\
\text { Distant metastasis associated }\end{array}$ & $\begin{array}{l}25(100 \%) \\
1(4 \%)\end{array}$ \\
\hline Time after primary tumor (months) & $30[4-384]$ \\
\hline $\begin{array}{l}\text { Indication of exenteration } \\
\text { Curative } \\
\text { Palliative }\end{array}$ & $\begin{array}{c}24(96 \%) \\
1(4 \%)\end{array}$ \\
\hline $\begin{array}{l}\text { Tumoral markers rate at time of ex } \\
\text { Scc } \\
\text { ACE } \\
\text { CA125 }\end{array}$ & $\begin{array}{l}1.5[0.6-27.2] \\
2[0.2-6] \\
14[6-71]\end{array}$ \\
\hline
\end{tabular}

[2 - 145]. One patient (4\%) was lost of follow-up. 13 patients $(52 \%)$ experienced a relapse within a median time of 7 months (range, 3 - 42). 11 deaths (44\%) were observed. Survival rates were higher in patients with cervical cancer than in patients with endometrial cancer. 1year OS was $82.1 \%$, (SE 8.1), 86\% (SE 9.1) for patients with cervical cancer and 45\% (SE 18.8) for patients with endometrial cancer ( $\mathrm{p} 0.019$ ). 1 year PFS was $61.4 \%$ (SE 10.1 ), 67.5\% (SE 12.1) for patients with cervical cancer and 50\% (SE 17.7) for patients with endometrial cancer (p 0.064). Follow-up and survival are summarized in Table 3 and Figure 1. 
Table 2. Characteristics of operative management and perioperative morbidity, $\mathrm{N}=25$.

\begin{tabular}{|c|c|}
\hline & $\begin{array}{l}\mathrm{N}(\%) \text { or median } \\
\text { [range] }\end{array}$ \\
\hline \multicolumn{2}{|l|}{ Type of resection } \\
\hline Total pelvic exenteration & $3(12 \%)$ \\
\hline Posterior exenteration & $8(32 \%)$ \\
\hline Anterior exenteration & $14(56 \%)$ \\
\hline Operation time (min) & $240[70-520]$ \\
\hline $\begin{array}{l}\text { Transfusion } \\
\text { N blood units }\end{array}$ & $\begin{array}{c}7(28 \%) \\
2[1-14]\end{array}$ \\
\hline Length of stay in intensive care unit (days) & $9.5[0-34]$ \\
\hline Lenfth of stay in hospital (days) & $22.5[7-74]$ \\
\hline \multicolumn{2}{|l|}{$\begin{array}{l}\text { Histopathological resection } \\
\text { (on curative procedures } N=24 \text { ) }\end{array}$} \\
\hline Complete & $22(92 \%)$ \\
\hline Positive margins & $2(8 \%)$ \\
\hline Urinary diversion & $17(68 \%)$ \\
\hline Incontinent ileoconduit (Bricker) & $15(60 \%)$ \\
\hline Continent ileoconduit (Kock) & $1(4 \%)$ \\
\hline Ureterosigmoidostomy (Coffey) & $1(4 \%)$ \\
\hline Colostoma & $8(32 \%)$ \\
\hline Temporary ileostomy & $4(16 \%)$ \\
\hline Temporary colostomy & $2(8 \%)$ \\
\hline Definitive colostomy & $2(8 \%)$ \\
\hline \multicolumn{2}{|l|}{ Additional procedure } \\
\hline Vulvectomy & $1(4 \%)$ \\
\hline Pelvic lymphadenectomy & $2(8 \%)$ \\
\hline \multicolumn{2}{|l|}{ Early complications (<2 months) } \\
\hline Peri-operative death & 0 \\
\hline Ileus & $6(24 \%)$ \\
\hline Wound infection & $7(28 \%)$ \\
\hline Insufficiency of intestinal anastomosis & $4(16 \%)$ \\
\hline Insufficiency of ureteral anastomosis & $3(12 \%)$ \\
\hline Pelvic abcess & $4(16 \%)$ \\
\hline Rectovaginal fistula & $1(4 \%)$ \\
\hline Peritonitis & $6(24 \%)$ \\
\hline Pyelonephritis & $2(8 \%)$ \\
\hline Thromboembolic events & $2(8 \%)$ \\
\hline Re-laparotomy & $9(36 \%)$ \\
\hline Late complications (>2 months) & $6(24 \%)$ \\
\hline Occlusion & $2(8 \%)$ \\
\hline Incisional hernia & $1(4 \%)$ \\
\hline Ureteral stenosis & $1(4 \%)$ \\
\hline Fistulas & $2(8 \%)$ \\
\hline \multicolumn{2}{|l|}{ Adjuvant treatment } \\
\hline Chemotherapy & $5(20 \%)$ \\
\hline Radiotherapy & $4(16 \%)$ \\
\hline
\end{tabular}

\subsection{Quality of Life}

Among the 13 patients contacted, 9 (69\%) completed the quality of life (QOL) questionnaires. Median age of patients who answered was 56 [range, 47 - 74]. Sexual functioning and sexual symptoms subscales were not completed since all patients declared having no sexual activity. On a scale of $0-100$, mean global QOL score was $45 \pm 17$. Interpretation of quality of life scores is developed in Figure 2. Global quality of life and func-
Table 3. Follow-up and survival rates.

\begin{tabular}{lc}
\hline & N (\%) or median [range] \\
\hline Follow up (months) & $40[2-145]$ \\
Lost to follow-up & $1(4 \%)$ \\
New relapse & $13(52 \%)$ \\
Time to relapse (months) & $7[3-42]$ \\
Death & $11(44 \%)$ \\
Overall survival (months) & $14[2-145]$ \\
$\quad$ Endometrial cancer & $13[4-42]$ \\
Cervical cancer & $20[2-145]$ \\
Progression free survival (months) & $12[2-145]$ \\
$\quad$ Endometrial cancer & $9.5[3-21]$ \\
$\quad$ Cervical cancer & $17[2-145]$ \\
\hline
\end{tabular}

tioning scores are summarized in Figure 2(a). Concerning symptoms scale, the most frequent symptoms experienced were insomnia, pain and fatigue with respective scores of 59,57 and 54 , on a scale of $0-100$. The score of financial difficulties due to health problems was 22 on a scale of $0-100$. Symptoms scales are summarized in Figure 2(b).

\section{DISCUSSION}

Despite good results in local control and no treatmentrelated death, we observed lower survival rates for patients with recurrent endometrial cancer compared to cervical cancer, and a low score of global quality of life.

Since 1948 and the first description of the technique, mortality rate of exenteration has decreased to $0 \%$ to $8 \%$ in the most recent studies, due to improvements in surgical techniques, increasing of reconstructive measures and refinement in intra-operative and postoperative medical management [12-19]. The highest mortality rate is reported by Fotopoulou et al. with a rate of $8.5 \%$ but the population of the study included $46.8 \%$ of palliative exenteration [14].

Morbidity rate varies from $32 \%$ to $84 \%$ in the literature with a re-intervention rate of $26 \%$ to $36 \%$ [12-21]. The most frequent early complications are infections (wound infection, pelvic abcess, pulmonary and urinary infections), transfusion, thromboembolic events and more specifically fistulas and anastomotic leakage. The most frequent late complications are intestinal occlusion and urinary stenosis. The most threatening complications are those involving the urinary tractus or the gastrointestinal system, depending on the type of reconstruction. Indeed, it is known that the rate of postoperative complications is correlated to the type of derivation [22]. The Bricker technique is one of the most used urinary diversion and is at risk of fistula since the intestinal loop used for the reconstruction has usually been irradiated [23]. The most frequent digestive derivation is the iliac colostoma but in most cases of posterior or total exenteration for gynae- 

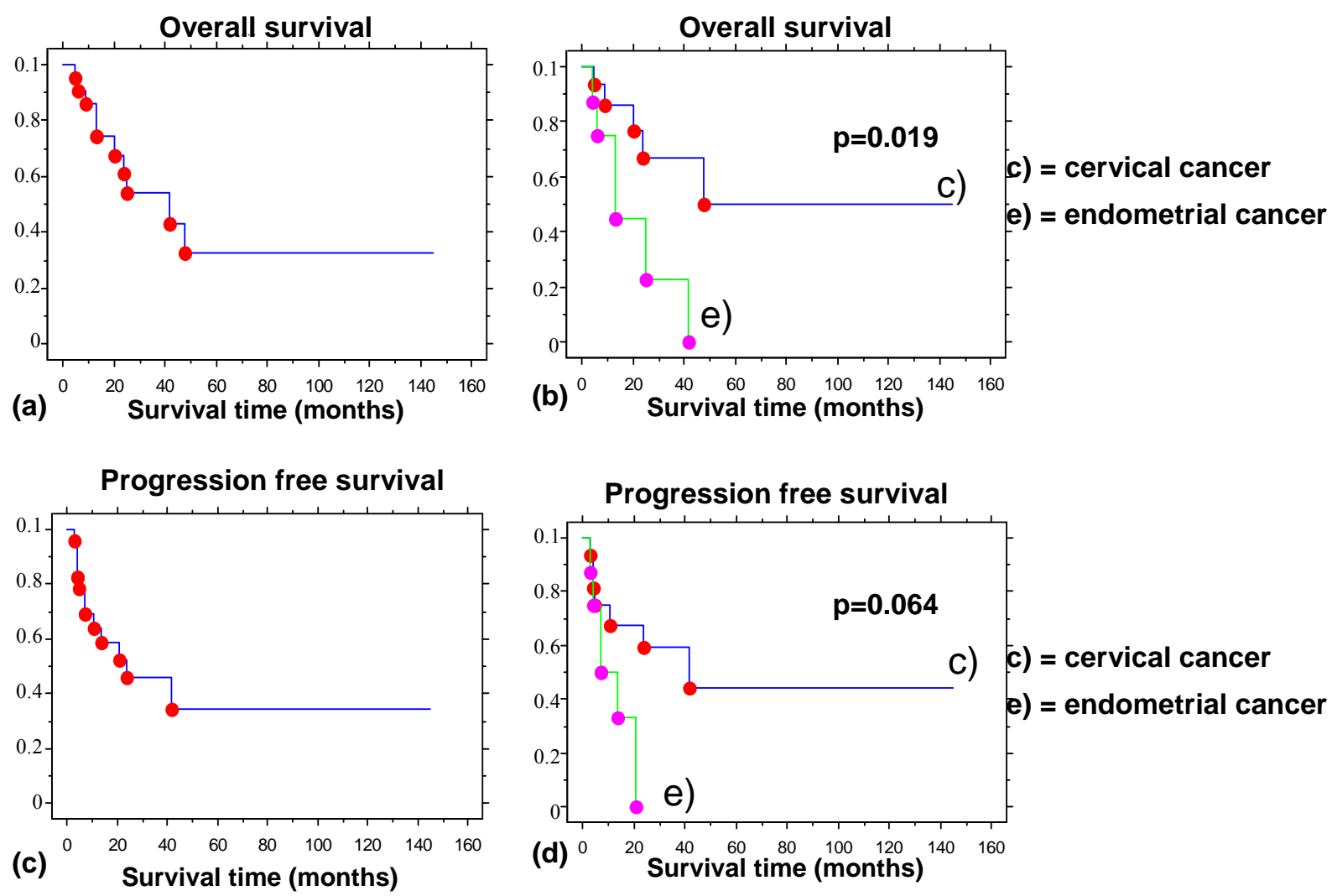

Figure 1. Survival rates after exenteration. (a) Overall survival rate; (b) Overall survival rates based on primary tumor; (c) Progression free survival rate; (d) Progression free survival rates based on primary tumor.
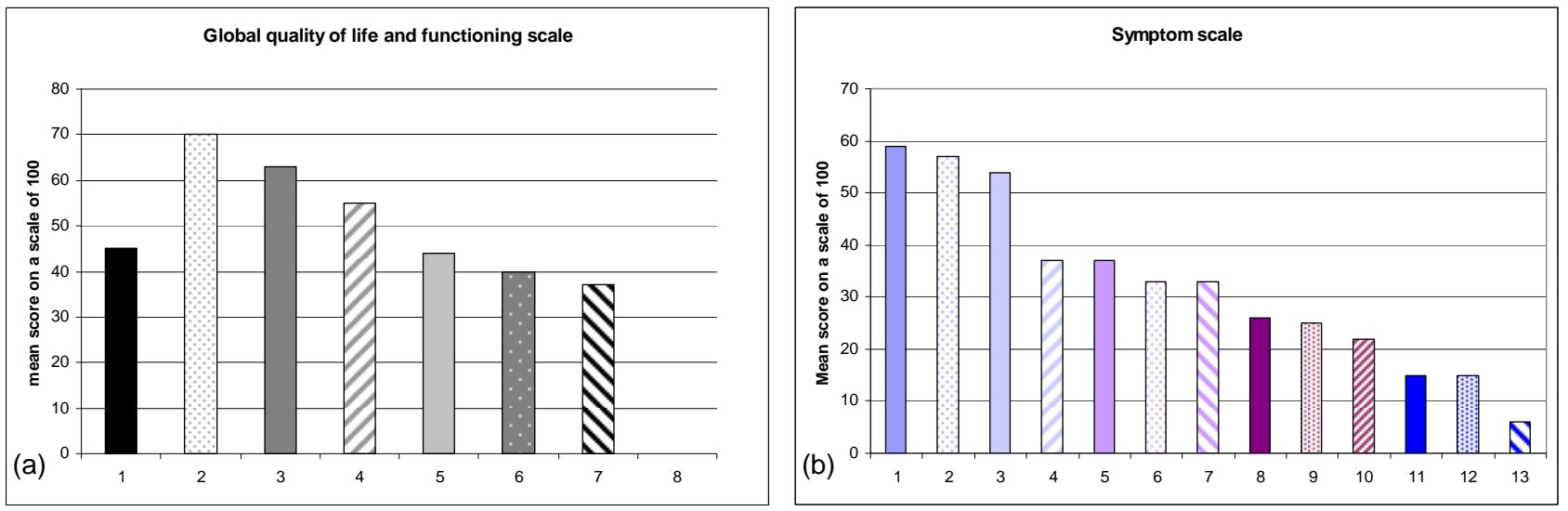

Figure 2. Quality of life. (a) Global quality of life and functioning scale: a higher score indicates a higher level of functioning or activity. 1) global quality of life; 2) cognitive functioning; 3) physical functioning; 4) emotional functioning; 5) role functioning; 6) social functioning; 7) body image; 8) sexual activity; (b) Symptom scale: a higher score indicates more symptoms. 1) insomnia; 2) pain; 3) fatigue; 4) dyspnea; 5) loss apetite; 6) constipation; 7) menauposal symptoms; 8) diarrhea; 9) symptoms experience; 10) financial difficulties; 11) peripheral neuropathy; 12) lymphoedema; 13) nausea and vomiting.

cological malignancies, a supraelevator colorectal anastomosis can be performed $(84 \%$ in exenteration for cervical cancer, $100 \%$ of exenteration for endometrial cancer) [24]. Our mortality and morbidity rates are concordant with literature, although comparison is awkward due to the heterogeneity of populations including curative and palliative exenterations, primary and second ex- enterations, cervical cancers and other types (endometrial, vaginal, vulvar etc...). A short review of recent studies is summarized in Table 4.

Our survival rates were also concordant with the literature. For patients with cervical cancer, we observed a 5 -year OS of $50 \%$ and a 5 -year PFS of $44.3 \%$. Maggioni et al. reported a 5-year OS of 50\% for cervical cancer, 
other studies reported 5-year OS ranging from 21\% to $66 \%$ but with more heterogeneous populations [4]. On a recent large study reporting 282 patients treated with pelvic exenteration for primary or recurrent cervical cancer, Schmidt et al. found 5-year OS of $41 \%$ with a morbidity rate of $26 \%$ [25]. For patients with recurrent endometrial cancer, we observed a worse prognosis compared to cervical cancer, such as Maggioni et al. [15]. Indeed, most of the recurrent endometrial cancers localized to the vaginal cuff are treated with external radiotherapy and/or brachytherapy. It is well known that recurrent endometrial cancer which can be treated only with pelvic exenteration are rare and of poorer prognosis [10,26,27]. In those series, 5-year overall survival rates varies from $14 \%$ to $56 \%$, and peri-operative mortality ranges from $0 \%$ to $13 \%[10,26,27]$.

Main reported factors associated with poor prognosis after pelvic exenteration are: margin status and size of the recurrence [4]. Patients with involved margins or close margins $(<1 \mathrm{~cm})$ display poorer prognosis with significantly decreased survival rate $[13,14,28]$. Patients with a non palpable recurrence have a 10 -year survival rate of $70 \%$, while this rate is of $48 \%$ if the recurrence is smaller than $3 \mathrm{~cm}$ and very limited with a recurrence larger than $3 \mathrm{~cm}$ [19]. Other factors have been associated with a poorer prognosis but with more controversial results. Prognosis might be impaired in case of: regional lymph node metastasis, pelvic side-wall involvement, adenocarcinoma compared to squamous cell carcinoma, vaginal, endometrial or vulvar primary tumours, recurrences occurring within less than 2 years after primary treatment [15-17,24,28]. Due to the small number of patients, we were not able to perform multivariate analysis in order to define prognostic factors.

Patients with cervical cancer have been reported to have lower global quality of life (QoL) scores than the general population and than patients with other gynaecological tumours $[29,30]$. Those studies were retrospec- tive. Prospective studies on quality of life of patients with cervical cancer or genital cancer displayed good global quality of life scores with variation according to the treatment $[31,32]$. Patients treated with surgery alone displayed better QoL than patients treated with surgery followed by adjuvant treatments (radiotherapy and/or chemotherapy) [32]. There are no difference in terms of global QoL between patients treated with Wertheim procedure and patients treated with pelvic exenteration, except for patients with two ostomies who report an impaired QoL [31]. Main alterations concern body image, self-confidence, and sexual function [31,32]. A recent prospective study on QoL after pelvic exenteration showed, on 11 patients, that most of patients returned to almost baseline functioning within a year [33]. This study is ongoing and these encouraging preliminary reslts need to be confirmed on a larger analysis. There is no published specific prospective study on quality of life after pelvic exenteration for recurrent gynecological cancer.

We report a global QoL score of 45, which is lower than the scores reported in literature. The main symptoms reported by our patients were: insomnia, pain and fatigue with respective scores of 59, 57 and 54 on a scale 0 - 100. Roos et al. reported a retrospective cohort study on 62 patients undergoing pelvic exenteration [34]. QoL was assessed in 32 patients with the EORTC-QLQ C30 and OV28 questionnaires [34]. They found good global QoL scores ranging from 64 to 75 on a scale of $0-100$ according to the follow-up period, compared with scores in healthy population (72 on a scale of 0 - 100) and in women with cervical cancer (65 on a scale of 0 - 100) $[34,35]$. As in our study, the main reported symptoms were insomnia, pain and fatigue with respective scores of 36, 22 and 37. However, comparison is still difficult because of the heterogeneity of the population including patients with bladder cancer, cervical cancer, vulvar cancer, endometrial and vaginal cancers [34]. Vaginal reconstruction has been reported to improve quality of life after

Table 4. Review of literature.

\begin{tabular}{|c|c|c|c|c|c|c|c|}
\hline & $\mathbf{N}$ & Period of treatment & Mortality & Major complication & Median follow-up & Overall survival & QOL \\
\hline Berek [18] & 75 & $1956-2001$ & $4 \%$ & & 50 months & 5 year OS $54 \%$ & NA \\
\hline Marnitz [16] & 55 & $1998-2004$ & $5 \%$ & $38 \%$ & & 5 year OS $36.8 \%$ & NA \\
\hline Fleisch [13] & 203 & 1983-2002 & $1 \%$ & $53 \%$ & 25 months & 5 year OS $21 \%$ & NA \\
\hline Maggioni [15] & 106 & $1996-2007$ & 0 & $45 \%$ & 22 months & 5 year OS $50 \%$ & NA \\
\hline Jurado [19] & 48 & $1988-2008$ & $0 \%$ to $2 \%$ & $65 \%$ to $73 \%$ & 115 months & 10 year DSS $20.5 \%$ & NA \\
\hline Fotopoulou [14] & 47 & 2003-2009 & $8.5 \%$ & $70.2 \%$ & 7 months & Median OS 10 months & NA \\
\hline McLean [17] & 44 & $1990-2008$ & 2 & & & OS $25 \%$ at 50 months & NA \\
\hline Benn [12] & 54 & $1990-2009$ & 0 & $50 \%$ & 12 months & Median OS 29 months & NA \\
\hline Schmidt [25] & 282 & 30 years & 0 & $26 \%$ & 17 months & 5 year OS $41 \%$ & NA \\
\hline This study & 25 & $1999-2011$ & 0 & $36 \%$ & 40 months & 5 year OS $31 \%$ & $\mathrm{~A}$ \\
\hline
\end{tabular}

OS: overall survival; DSS: disease specific survival; NA: not analyzed; A: analyzed. 
pelvic exenteration by providing a possible sexual function and by increasing woman's self confidence $[31,36]$. Despite specific associated morbidity, most of patients would advise others to undergo vaginal reconstruction even if less than $50 \%$ of them report a sexual activity after surgery [34,37]. In case of vaginal reconstruction, sexual activity is better in patients under 40 years old, in case of supraelevator exenteration and if patients had a sexual activity before surgery [36]. Our low score of global quality of life could be partly explained by the absence of vaginal reconstruction but most of our patients were older than 50 and there is no standard recommendation concerning vaginal reconstruction. The limitation of our study is the small number of patients, and, as most of the studies, it is retrospective without baseline evaluation of quality of life and with cross-sectional analyses at varying time interval after treatment. Results of a French multicentric prospective analysis of quality of life in those specific patients are eagerly awaited and should be soon published [38].

\section{CONCLUSION}

Pelvic exenteration is the only therapeutic option providing an expectancy to cure recurrent cervical cancer with good local control and survival rates. Nevertheless, it remains an extensive surgery with high peri-operative morbidity and with physical, emotional, social and sexual sequels impairing the quality of life. Quality of life should be systematically assessed before surgery, and post surgical problems should be discussed with patients and families with the cooperation of multidisciplinary teams. Vaginal reconstruction should be proposed to young patients when possible. The option of isolated perfusion of the pelvis could represent an alternative to mutilating surgical procedures or could be used to control unresectable patients but this technique still needs further evaluation [39]. Given all these consequences, in palliative indications and in case of endometrial cancer recurrences which can not be treated with radiotherapy, best supportive care should be put in balance with pelvic exenteration.

\section{ACKNOWLEDGEMENTS}

The authors are indebt to Dr Laure Copel for her counselling about quality of life questionnaires analysis.

\section{REFERENCES}

[1] Hockel, M. and Dornhofer, N. (2006) Pelvic exenteration for gynaecological tumours: Achievements and unanswered questions. The Lancet Oncology, 7, 837-847. doi:10.1016/S1470-2045(06)70903-2

[2] Perez, C.A., Grigsby, P.W., Nene, S.M., Camel, H.M., Galakatos, A., Kao, M.S. and Lockett, M.A. (1992) Ef- fect of tumor size on the prognosis of carcinoma of the uterine cervix treated with irradiation alone. Cancer, 69, 2796-806.

doi:10.1002/1097-0142(19920601)69:11<2796::AID-CN CR2820691127>3.0.CO;2-O

[3] Resbeut, M., Fondrinier, E., Fervers, B., Haie-Meder, C., Bataillard, A., Lhomme, C., Asselain, B., Basuyau, J.P., Bremond, A., Castaigne, D., Dubois, J.B., Houvenaeghel, G., Lartigau, E., Leblanc, E., Sastre-Garau, X., Sarradet, A., Guastalla, J.P. and Chauvergne, J. (2003) Standards, Options and Recommendations for the management of invasive cervical cancer patients (non metastastic). Bulletin du Cancer, 90, 333-346.

[4] Peiretti, M., Zapardiel, I., Zanagnolo, V., Landoni, F., Morrow, C.P. and Maggioni, A. (2012) Management of recurrent cervical cancer: A review of the literature. Surgical Oncology, 21, e59-e66.

doi:10.1016/j.suronc.2011.12.008

[5] Burke, T.W., Heller, P.B., Woodward, J.E., Davidson, S.A., Hoskins, W.J. and Park, R.C. (1990) Treatment failure in endometrial carcinoma. Obstetrics \& Gynecology, 75, 96-101.

[6] Berchuck, A., Anspach, C., Evans, A.C., Soper, J.T., Rodriguez, G.C., Dodge, R., Robboy, S. and Clarke-Pearson, D.L. (1995) Postsurgical surveillance of patients with FIGO stage I/II endometrial adenocarcinoma. Gynecologic Oncology, 59, 20-24. doi:10.1006/gyno.1995.1262

[7] Creutzberg, C.L., van Putten, W.L., Koper, P.C., Lybeert, M.L., Jobsen, J.J., Warlam-Rodenhuis, C.C., De Winter, K.A., Lutgens, L.C., van den Bergh, A.C., van der SteenBanasik, E., Beerman, H. and van Lent, M. (2003) Survival after relapse in patients with endometrial cancer: Results from a randomized trial. Gynecologic Oncology, 89, 201-209. doi:10.1016/S0090-8258(03)00126-4

[8] Creutzberg, C.L. (2004) GOG-99: Ending the controversy regarding pelvic radiotherapy for endometrial carcinoma? Gynecologic Oncology, 92, 740-743.

doi:10.1016/j.ygyno.2004.01.009

[9] Creutzberg, C.L., van Putten, W.L., Warlam-Rodenhuis, C.C., van den Bergh, A.C., de Winter, K.A., Koper, P.C., Lybeert, M.L., Slot, A., Lutgens, L.C., Stenfert Kroese, M.C., Beerman, H. and van Lent, M. (2004) Outcome of high-risk stage IC, grade 3, compared with stage I endometrial carcinoma patients: The postoperative radiation therapy in endometrial carcinoma trial. Journal of Clinical Oncology, 22, 1234-1241. doi:10.1200/JCO.2004.08.159

[10] Campagnutta, E., Giorda, G., De Piero, G., Sopracordevole, F., Visentin, M.C., Martella, L. and Scarabelli, C. (2004) Surgical treatment of recurrent endometrial carcinoma. Cancer, 100, 89-96. doi:10.1002/cncr.11868

[11] Brunschwig, A. (1948) Complete excision of pelvic viscera for advanced carcinoma; a one-stage abdominoperineal operation with end colostomy and bilateral ureteral implantation into the colon above the colostomy. Cancer, 1, 177-183.

doi:10.1002/1097-0142(194807)1:2<177::AID-CNCR28 20010203>3.0.CO;2-A 
[12] Benn, T., Brooks, R.A., Zhang, Q., Powell, M.A., Thaker, P.H., Mutch, D.G. and Zighelboim, I. (2011) Pelvic exenteration in gynecologic oncology: A single institution study over 20 years. Gynecologic Oncology, 122, 14-18. doi:10.1016/j.ygyno.2011.03.003

[13] Fleisch, M.C., Pantke, P., Beckmann, M.W., Schnuerch, H.G., Ackermann, R., Grimm, M.O., Bender, H.G. and Dall, P. (2007) Predictors for long-term survival after interdisciplinary salvage surgery for advanced or recurrent gynecologic cancers. Journal of Surgical Oncology, 95, 476-484. doi:10.1002/jso.20686

[14] Fotopoulou, C., Neumann, U., Kraetschell, R., Schefold, J.C., Weidemann, H., Lichtenegger, W. and Sehouli, J. (2010) Long-term clinical outcome of pelvic exenteration in patients with advanced gynecological malignancies. Journal of Surgical Oncology, 101, 507-512. doi:10.1002/jso.21518

[15] Maggioni, A., Roviglione, G., Landoni, F., Zanagnolo, V., Peiretti, M., Colombo, N., Bocciolone, L., Biffi, R., Minig, L. and Morrow, C.P. (2009) Pelvic exenteration: Tenyear experience at the European Institute of Oncology in Milan. Gynecologic Oncology, 114, 64-68. doi:10.1016/i.ygyno.2009.03.029

[16] Marnitz, S., Kohler, C., Muller, M., Behrens, K., Hasenbein, K. and Schneider, A. (2006) Indications for primary and secondary exenterations in patients with cervical cancer. Gynecologic Oncology, 103, 1023-1030. doi:10.1016/j.ygyno.2006.06.027

[17] McLean, K.A., Zhang, W., Dunsmoor-Su, R.F., Shah, C.A., Gray, H.J., Swensen, R.E. and Goff, B.A. (2011) Pelvic exenteration in the age of modern chemoradiation. Gynecologic Oncology, 121, 131-134. doi:10.1016/j.ygyno.2010.11.044

[18] Berek, J.S., Howe, C., Lagasse, L.D. and Hacker, N.F. (2005) Pelvic exenteration for recurrent gynecologic malignancy: Survival and morbidity analysis of the 45-year experience at UCLA. Gynecologic Oncology, 99, 153159. doi:10.1016/j.ygyno.2005.05.034

[19] Jurado, M., Alcazar, J.L. and Martinez-Monge, R. (2010) Resectability rates of previously irradiated recurrent cervical cancer (PIRCC) treated with pelvic exenteration: Is still the clinical involvement of the pelvis wall a real contraindication? A twenty-year experience. Gynecologic Oncology, 116, 38-43. doi:10.1016/j.ygyno.2009.09.035

[20] Sharma, S., Odunsi, K., Driscoll, D. and Lele, S. (2005) Pelvic exenterations for gynecological malignancies: Twenty-year experience at Roswell Park Cancer Institute. International Journal of Gynecological Cancer, 15, 475482. doi:10.1111/j.1525-1438.2005.15311.x

[21] Pawlik, T.M., Skibber, J.M. and Rodriguez-Bigas, M.A. (2006) Pelvic exenteration for advanced pelvic malignancies. Annals of Surgical Oncology, 13, 612-623. doi:10.1245/ASO.2006.03.082

[22] Soper, J.T., Berchuck, A., Creasman, W.T. and ClarkePearson, D.L. (1989) Pelvic exenteration: Factors associated with major surgical morbidity. Gynecologic Oncology, 35, 93-98. doi:10.1016/0090-8258(89)90020-6

[23] Bladou, F., Houvenaeghel, G., Delpero, J.R. and Guerinel, G. (1995) Incidence and management of major urinary complications after pelvic exenteration for gynecological malignancies. Journal of Surgical Oncology, 58, 91-96. doi:10.1002/jso.2930580204

[24] Moutardier, V., Houvenaeghel, G., Lelong, B., Mokart, D. and Delpero, J.R. (2003) Colorectal function preservation in posterior and total supralevator exenteration for gynecologic malignancies: An 89-patient series. Gynecologic Oncology, 89, 155-159. doi:10.1016/S0090-8258(03)00069-6

[25] Schmidt, A.M., Imesch, P., Fink, D. and Egger, H. (2012) Indications and long-term clinical outcomes in 282 patients with pelvic exenteration for advanced or recurrent cervical cancer. Gynecologic Oncology, 125, 604-609. doi:10.1016/j.ygyno.2012.03.001

[26] Barakat, R.R., Goldman, N.A., Patel, D.A., Venkatraman, E.S. and Curtin, J.P. (1999) Pelvic exenteration for recurrent endometrial cancer. Gynecologic Oncology, 75, 99-102. doi:10.1006/gyno.1999.5536

[27] Morris, M., Alvarez, R.D., Kinney, W.K. and Wilson, T.O. (1996) Treatment of recurrent adenocarcinoma of the endometrium with pelvic exenteration. Gynecologic Oncology, 60, 288-291. doi:10.1006/gyno.1996.0040

[28] Forner, D.M., Lampe, B. (2011) Exenteration as a primary treatment for locally advanced cervical cancer: Long-term results and prognostic factors. American Journal of Obstetrics \& Gynecology, 205, 148e1-e6.

[29] Park, S.Y., Bae, D.S., Nam, J.H., Park, C.T., Cho, C.H., Lee, J.M., Lee, M.K., Kim, S.H., Park, S.M. and Yun, Y.H. (2007) Quality of life and sexual problems in disease-free survivors of cervical cancer compared with the general population. Cancer, 110, 2716-2725. doi:10.1002/cncr.23094

[30] Distefano, M., Riccardi, S., Capelli, G., Costantini, B., Petrillo, M., Ricci, C., Scambia, G. and Ferrandina, G. (2008) Quality of life and psychological distress in locally advanced cervical cancer patients administered preoperative chemoradiotherapy. Gynecologic Oncology, 111, 144-150. doi:10.1016/j.ygyno.2008.06.034

[31] Hawighorst-Knapstein, S., Fusshoeller, C., Franz, C., Trautmann, K., Schmidt, M., Pilch, H., Schoenefuss, G., Knapstein, P.G., Koelbl, H., Kelleher, D.K. and Vaupel, P. (2004) The impact of treatment for genital cancer on quality of life and body image-Results of a prospective longitudinal 10-year study. Gynecologic Oncology, 94, 398403. doi:10.1016/j.ygyno.2004.04.025

[32] Ferrandina, G., Mantegna, G., Petrillo, M., Fuoco, G., Venditti, L., Terzano, S., Moruzzi, C., Lorusso, D., Marcellusi, A. and Scambia, G. (2012) Quality of life and emotional distress in early stage and locally advanced cervical cancer patients: A prospective, longitudinal study. Gynecologic Oncology, 124, 389-394. doi:10.1016/j.ygyno.2011.09.041

[33] Rezk, Y.A., Hurley, K.E., Carter, J., Dao, F., Bochner, B.H., Aubey, J.J., Caceres, A., Einstein, M.H., AbuRustum, N.R., Barakat, R.R., Makker, V. and Chi, D.S. (2013) A prospective study of quality of life in patients undergoing pelvic exenteration: Interim results. Gynecologic Oncology, 128, 191-197. doi:10.1016/j.ygyno.2012.09.030 
[34] Roos, E.J., de Graeff, A., van Eijkeren, M.A., Boon, T.A. and Heintz, A.P. (2004) Quality of life after pelvic exenteration. Gynecologic Oncology, 93, 610-614. doi:10.1016/j.ygyno.2004.03.008

[35] Fayers, P.W.S. and Curran, D. (1998) EORTC QLQ-C30. Reference values. European Organisation for Research and Treatment of Cancer.

[36] Magrina, J.F., Stanhope, C.R. and Weaver, A.L. (1997) Pelvic exenterations: Supralevator, infralevator, and with vulvectomy. Gynecologic Oncology, 64, 130-135. doi:10.1006/gyno.1996.4532

[37] Ratliff, C.R., Gershenson, D.M., Morris, M., Burke, T.W., Levenback, C., Schover, L.R., Mitchell, M.F., Atkinson, E.N. and Wharton, J.T. (1996) Sexual adjustment of patients undergoing gracilis myocutaneous flap vaginal re- construction in conjunction with pelvic exenteration. Cancer, 78, 2229-2235.

doi:10.1002/(SICI)1097-0142(19961115)78:10<2229::AI D-CNCR27>3.0.CO;2-\#

[38] Martinez, A.F.T., Filleron, T., Rouanet, P., Meeus, P., Houvenaeghel, G. and Classe, J.M. Quality of life after exenteration. Gynecologic Oncology, in Press.

[39] Bonvalot, S., de Baere, T., Mendiboure, J., Paci, A., Farace, F., Drouard-Troalen, L., Bonnet, L., Hakime, A., Bonniaud, G., Raynard, B., Israel, P., Le Cesne, A., Eggermont, A.M., Laplanche, A. and Muret, J. (2012) Hyperthermic pelvic perfusion with tumor necrosis factoralpha for locally advanced cancers: Encouraging results of a phase II study. Annals of Surgery, 255, 281-286. doi:10.1097/SLA.0b013e318242ebe7 